\title{
Fuzzy Logic Applied to Track Generation Areas of Swell Systems Observed by SAR
}

\author{
E.G.G. de Farias ${ }^{1}$, J.A. Lorenzzetti ${ }^{1}$, A. Bentamy ${ }^{2}$, B.Chapron, B $^{2}$. and H. Romain ${ }^{3}$
}

\author{
${ }^{1}$ National Institute for Space Research, INPE Remote Sensing Division, Sao Josédos Campos 12227-010, Brazil \\ 2 IFREMER, Laboratoire d'Ocanographie Spatiale, Plouzané 70 29280, France \\ ${ }^{3}$ Collecte Localisation Satellite (CLS), Plouzané 70 29280, France \\ *: Corresponding authors : email address: gentil@dsr.inpe.br ; loren@dsr.inpe.br ; \\ abderrahim.bentamy@ifremer.fr ; bertrand.chapron@ifremer.fr ; rhusson@cls.fr
}

\begin{abstract}
:
Recently, with the availability of a great number of synthetic aperture radar (SAR) wave mode spectra, it has been possible to derive a set of great circle lines of swell propagation whose intersection points indicate the position of the storm generating the observed swell field. However, due to the inherent limitations of SAR spectra, the locus of convergence of great circle of swell propagation can be sometimes diffuse or contain multiple convergence regions. In this letter, we adapted the fuzzy cluster logic method to identify the regions of convergence of SAR wave field rays. The analysis of the results of the fuzzy algorithm clearly indicates the ability of this statistical method to identify the cluster center region of swell fields observed in SAR wave mode images. The measure of success of the method was how well the generation center of the swell could be traced back to an existing strong storm system.
\end{abstract}

Keywords: Swell wave fields and fuzzy logic ; synthetic aperture radar (SAR)

\section{Introduction}

The wave field generated by severe storms are difficult to be accurately modeled [1]. From strong storms centers, swell systems propagate for long distances showing very little dissipation [2]. With the possibility of using sequences of directional wave spectra obtained from space-borne Synthetic Aperture Radar (SAR) Wave Mode images it is now possible to derive routinely a set of great circle lines of swell propagation. The intersection points of these lines can be used to indicate the possible region of the storm that generated the observed swell field [3], [4]. However, due to inherent uncertainties and limitations of a SAR spectra such as the non-linear mapping of sea surface wave spectrum into a SAR image spectrum [5], [6], the method used for determining SAR spectrum peak 
period and wave propagation direction, among others, the locus of convergence of great circle of swell propagation can sometimes be diffuse, or contain multiple convergence regions.

Considering the inherent inaccuracies of the data, the mathematical determination of the "best" convergence region of a large number of great circle lines of swell propagation is not simple. The statistical approach of fuzzy cluster logic is here proposed as a possible and novel solution for this problem. In this study, we adapted an unsupervised Fuzzy Cluster Logic (FCL) method to identify the regions of convergence of the SAR wave field rays. The FCL method is normally used in digital image pattern recognition, but it has also been applied for the analysis of oceanic satellite data [7].

We present below an analysis of a series of ASAR/Envisat wave mode spectra for swell propagation in the Atlantic ocean using the FCL method with the objective of showing its efficacy to determine the source regions of observed swell wave fields.

We want to show that the proposed methodology is simple to be implemented, robust and can be a powerful tool to identify the swell generation regions for large oceanic areas. The results obtained are illustrated for a few case studies in which we compare the SAR located storm source regions with scatterometer wind (QuikScat) data.

\section{DATA AND Methods}

\section{A. ASAR Wave Mode data}

The European Space Agency (ESA) ENVISAT ASAR derived spectra used in this paper are Level 2 products provided by the Centre ERS dArchivage et de Traitment (CERSAT) at Ifremer (France). The processing methodology used to derive the wave spectra is described in detail by [8] [9].

The ASAR Wave Mode Level 2 directional spectra are given on a log-polar grid in wavenumber and direction domains, $F(k, \phi)$. Nominal directional resolution is $10^{\circ}$ and wavenumbers are given in logarithmic scale corresponding to a nomimal wavelength range between 30 and $800 \mathrm{~m}$ [9]. The frequency $F(\mathrm{f})$ and directional spectra, $\Psi(\phi)$ can then derived from the Level 2 spectra product. We used in this investigation a set of 10640 ASAR directional spectra covering the period 2003 to 2009 and for the Atlantic sector between $10^{\circ} \mathrm{S} 60^{\circ} \mathrm{N}$ and $10^{\circ} \mathrm{E}$ $80^{\circ} \mathrm{W}$. The spectra are provided in a grid of $100 \mathrm{~km}$ in the along track direction and $7^{\circ}$ in the longitudinal direction. The geophysical validation of the satellite wave fields shows good agreement in terms of statistical wave parameters in comparison with WAM model [10].

\section{B. Scatterometer data}

The vector surface winds derived from the QuikScat satellite SeaWinds scatterometer used in this study were also provided by CERSAT and are retrieved from scatterometer measurements and interpolated in space and time as regular gridded fields at a spatial resolution of $25 \times 25 \mathrm{~km}$ and daily mean. The QuikScat provides neutral equivalent wind vectors (speed and direction) at a reference level of $10 \mathrm{~m}$ above sea surface [11]. All QuikScat wind data used in this paper correspond to L2b products processed routinely by Jet Propulsion Laboratory (JPL). 
The accuracy of the QuikScat winds has been investigated in a number of papers through comparisons against in-situ wind measurements (buoy and ships) [12], [13], [14], [15], [16]. The correlation coefficients between satellite and in-situ data for wind speeds and directions exceed 0.90 and 0.88 for wind speeds in the range of 0 to $30 \mathrm{~ms}^{-1}$ [17], respectively. The associated rms differences are about $1 \mathrm{~ms}^{-1}$ and $18^{\circ}$.

\section{Fuzzy C-Means Analysis (Fuzzy Logic Clustering)}

In contrast to classical set theory where an element either belongs or not to a set, fuzzy set theory allows an element to have membership to one or more sets. [18] introduced fuzzy set theory in a mathematical context to handle imprecise information. In this context it is possible to extend the concepts of classical set theory allowing for partial or intermediate set membership values. It also allows for full ("crisp" or "hard") memberships, being therefore a superset of classical set theory.

If we consider one universe that contains elements $x$ that follow a rule given by $S=\{x\}$, under normal set theory the membership function $\mathrm{f}_{A}(\mathrm{x})$, is either 1 or 0 , if $\mathrm{x}$ belongs or not to a subset of A of $\mathrm{S}$, Under fuzzy set theory, the membership function is altered to allow for graded memberships and is transformed into $0 \leq f_{i}(x) \leq 1$. Thus it is possible to obtain the partial set membership for each fuzzy set. In this sense $f_{i}(x)$ represents the probability that $\mathrm{x}$ belongs to the ith set. If there are c possible sets, then;

$$
\sum_{i=1}^{c} f_{i}(x)=1
$$

The Fuzzy C-Means (FCM) algorithm used here is a fuzzy technique developed by [19] and improved by [20]. Frequently used in pattern recognition, the fuzzy technique is a method of clustering which allows one piece of data to belong to two or more clusters. In the most general case, clusters are defined as groups of points that are similar according to some measure of similarity. Usually, similarity is defined as proximity of the points according to a distance function.

Clusters representing one specific class in which each member has full membership, that is, they do not belong to any other class, are called discontinuous or discrete classes. On the other hand, classes in which each member may belong in some extent to every cluster or a partition are called continuous classes [21]. These classes are a generalization of the fuzzy set theory, and may have membership values ranging between 0 and 1 , where 1 represents the membership cluster center and 0 represents complete dissociation to the cluster.

The FCM algorithm attempts to minimize the objective function $J_{m}$;

$$
J_{m}=\sum_{j=1}^{N_{s}} \sum_{i=1}^{N_{c}} \mu_{i j}^{m} d^{2}\left(X_{j} V_{i}\right)
$$

where: $N_{s}$ is the total number of observations $\mathrm{j}$ in the data set; $N_{c}$ is the number of separate clusters, $\mathrm{i} ; \mathrm{d}$ is the Euclidean distance between an observation vector $X_{j}$ and cluster center $V_{i} ; \mu_{i j}$ is the membership value of the $j^{\text {th }}$ observation to the $i^{\text {th }}$ cluster (a value between 0 and 1); and $\mathrm{m}$ is the weighting exponent (initially set to 2 ). High membership values indicates strong likelihood for the studied variable to be present at the cluster. The FCM 
method allows a parameter to be part of more than one cluster. In our work we used only two data class clusters (1 - a storm generation region and 2 - not a generation region).

\section{Swell Source Identification by Back Propagation}

From the ASAR wave mode product one can estimate the wave spectrum at a specific region, the peak period and direction of propagation of the dominant wave field. From this information it is possible to use the physical properties of the swell waves to propagate them backwards in time to estimate their generation region. [22] and [4] showed that this methodology allows the tracking of swell fields in a range of 3 to 10 days. These studies have demonstrated that the combination of SAR images at different times and places allows for the prediction of arrivals of gravity waves in coastal regions, and to monitor the propagation patterns of wave fields.

Starting from a initial geographic position $\phi_{0}, \lambda_{0}$ (longitude and latitude) and the direction of propagation $\theta_{o}$, as obtained from a SAR wave directional spectrum, the swell field great circle trajectory in deep water can be evaluated at a distance $\mathrm{X}$ and at a time $\mathrm{t}$ by $X=\left(t-t_{o}\right) \cdot C_{g}=\left(t-t_{o}\right) \cdot g /(4 \pi f)$, where $C_{g}$ is the deep water group velocity (estimated from $T_{p}$ ), $f$ is the spectra peak frequency and $t_{o}$ is the time of SAR observation. This corresponds to a spherical distance $\alpha=X / R$ along the great circle, where $\mathrm{R}$ is the radius of the Earth. Figure 1 indicates the complexity one is faced when trying to identify the generation zone of a particular swell field using the backward propagation from a series of observed wave mode image spectra.

Here we use sequences of SAR Wave Mode spectra solely to identify the formation region of observed swell fields. For this, we generate from each Wave Mode spectra the backward trajectory using the great circle approach. The probable location of swell generation is defined as the convergence zone of the different trajectories for similar times.

We initiate the processing using all satellite tracks passing through the study region within an established time interval; tests indicated that 3 days was the best choice. Thus, all ASAR Wave Mode spectra present in the CERSAT database for the study region and for the chosen three day period were included for each specific case study. In each case analyzed, between 250-400 ASAR wave spectra were used. The initial pre-processing included the extraction from each spectra its geographical location, the peak period and propagation direction. In the sequence the back propagation of each swell field was done using the above described methodology. In this study we choose a backward propagation time step of 2 hours. Thus for each spectra, a set of propagation points is generated. All trajectories coincident points (intersection points) were captured along all the back propagation fields. Normally, this resulted in a set of about $3 \times 10^{3}$ intersection points per case study. A small fraction of the derived trajectories do not converge, however, to the same regions. These isolated intersection points, normally associated with higher frequency wind-sea waves, were considered spurious for the swell storm generation analysis and were discarded.

The collected coincident points, $\mathrm{X}_{j}$ in equation (2), were then used in the fuzzy C-means algorithm to determine the spatial clusters. We used in this study three variables: latitude, longitude and time, of each back propagating swell great circle points. After testing different cluster numbers $\left(\mathrm{N}_{c}\right.$ in equation (2)) we observed that best results, i.e., better defined clusters, were obtained using two clusters. The cluster that shows the highest convergence of 
points in space is assumed corresponding to the swell generation region. The second cluster (normally with a much more diffuse spreading of points) is discarded in the analysis.

As explained above, the membership values are allowed to vary from 0 to 1 for each cluster; the maximum value corresponding to the center of the cluster. We take the region next to the center of the cluster as the swell generation region. We have set this region being limited by membership values between 0.95 and 1 . All other points corresponding to smaller memberships were filtered out.

To verify the consistency of the fuzzy model we plotted the estimated swell generation region $\left(0.95 \leq f_{i}(x) \leq 1\right)$ over a map of corresponding scatterometer wind data. The presence of strong winds or storm center coincident with fuzzy derived cluster analysis was used as a validation of the method.

\section{RESULTS AND DISCUSSION}

From the Level 2 ASAR directional spectra available at CERSAT for the years 2003-2009, for the study region, we were able to test the FCM method for almost 40 cases. The main motivation was to verify whether the fuzzy clusters determined in an unsupervised algorithm had a consistency when compared against strong wind generation areas, possible candidates responsible for the observed swell fields. In the following we present and discuss four of these case studies.

Figure 2 shows the swell back propagaton intersection points and their membership values relative to cluster 1 (in color) obtained from ASAR spectra from days 25, 26 and 27 January, 2003. The intersection points corresponds approximately to a decimation of $50 \%$ of total number of back propagation points analyzed. Note that a well defined region, with membership values near 1 , is identifyed by the fuzzy algorithm. We claim that this high membership zone can be used as the generation region of the observed swell. The high membership region corresponds to January 24, 2003.

Figure 3 shows the results obtained by the method for January, 2003 (described above), February 2004, March 2005 and January 2008, where regions of high membership values (above 0.95) are superimposed over QuikScat wind fields. A clearer delimitation of the swell source region is obtained by filtering out all points with membership values less than 0.95 . Observe that the fuzzy centers are located at oceanic regions showing very high winds, ranging from $22 \mathrm{~ms}^{-1}$ for case B to $26 \mathrm{~ms}^{-1}$ for case C. For cases A and D, the fuzzy centers were located almost on top of a closed storm center. For cases B and C, although not coincident with storm center. the fuzzy centers were located near maximum winds. Table 1 shows the distances of the fuzzy centers (membership $=1$ ) and the storm centers given by scatterometer wind data. Note that the greatest distance observed between the databases is $3.5^{\circ}$. We noticed in analyzing all 40 cases that fuzzy cluster maximum is able to precisely pinpoint storm center when it is sharply defined. When storm center is more diffuse the fuzzy algorithm is still, in the majority of cases capable of capturing its neighboring area. Another possible cause of fuzzy center being displaced to observed QuikScat storm center is the rapid displacement of some of these storms.

Long period and high significant wave height swell systems have been observed in the Norwegian Sea shelf region having their origin in strong storms present is the northwestern Atlantic [23]. Normally these swell events 
were observed being generated by intense extra tropical cyclonic storms that move rapidly towards northeast. The cases presented before fit to this scenario, that is, the SAR observed swell systems were generated in the NW Atlantic by strong low pressure systems moving from SW to NE. [24] shows strong wave fields associated to the climatology of local NH winter storms. High winds associated with the low pressure systems passing through the mid-latitude storm tracks generate large wind waves with high peak phase speeds. Normally, the result of this is a southward propagation of swell systems out of the storm tracks during the NH winter [24]. Throughout the year the high winds along the North Atlantic storm tracks are more intense in January, February and March. Therefore, it is expected that swell originates predominantly from these regions during this period [25].

\section{CONCLUSiOnS}

The analysis of the results of the fuzzy algorithm applied to our database of SAR wave spectra clearly indicates the ability of the unsupervised fuzzy statistical method to identify the cluster center regions of swell fields observed in SAR wave mode images. The measure of success of the method was how well the generation center of the swell could be traced back to an existing strong storm system. Out of a total of about 40 case studies for the years 2003 and 2009, the fuzzy algorithm showed good results for about $90 \%$ of the tests cases. The unsuccessful cases seemed to be related to high frequency wind-sea dominant cases and very little swell trajectory convergence.

It should be noted, however, that for cases where only weak weather systems are present, it can happen that the intersection points of great circle propagation are rather diffuse and the algorithm is not capable of converging to a tight generation region.

Since coincident points used for the definition of the fuzzy center include measurements at different times for the same day, the results obtained are suitable only for a daily average estimate, i.e., the storm center obtained represents an average position of the storm during the day.

The accuracy of the method is expected to be much better for swell waves than for wind sea systems since SAR wave mode spectra is much more reliable under the linear imaging mechanism in the long wave spectral domain [26], [8]. However, considering that swell systems are much more predominant in the global ocean [27], with the few exceptions of enclosed or semi-enclosed seas [24], the proposed method can be a useful tool to study wave propagation systems.

Accurate analysis of swell propagation is an important factor in evaluating potentially hazardous conditions for ocean and coastal zones. To our knowledge this is the first application of fuzzy methodology to identifying swell storm generation regions. The method here proposed can be implemented to run in a completely autonomous mode in a normal desktop computer in less than one hour per case. This method can be used to check the origin of strong long period waves and additionally as a tool to validate weather forecast and wave models accuracies. If sufficiently long series of SAR wave mode spectra are available, the application of the method can be used to improve the climatology of swell generating regions in the global ocean.

\section{REFERENCES}

[1] W. Group, "Wave modelling - the state of the art," Progress in Oceanography, vol. 75, pp. 603-674, 2007. 
[2] W. H. Munk, G. R. Miller, F. E. Snodgrass, and N. F. Barber, "Directional recording of swell from distant storms," Phil. Trans. Roy. Soc. London A, vol. 255, pp. 505-584, 1963.

[3] P. Heimbach and K. Hasselmann, Development and application of satellite retrievals of ocean wave spectra. Amsterdam: Satellites, oceanography and society, 2000.

[4] F. Collard, F. Ardhuin, and B. Chapron, "Monitoring and analysis of ocean swell fields from space: New methods for routine observations," JGR, vol. 114, pp. 1-15, 2009.

[5] W. Alpers, D. Ross, and C. Rufenach, "On the detectability of ocean surface waves by real and Synthetic Aperture Radar," JGR, vol. 86, pp. 6481-6498, 1981.

[6] K. Hasselmann and S. Hasselmann, "On the nonlinear mapping of an ocean wave spectrum into a Synthetic Aperture Radar image spectrum and its inversion," JGR, vol. 96, pp. 10713-10729, 1991.

[7] T. S. Moore, J. W. Campbell, and H. Feng, "A Fuzzy logic classification scheme for selecting and blending satellite ocean color algorithms," IEEE Transactions on Geoscience and Remote Sensing, vol. 39, pp. 1764-1776, 2001.

[8] B. Chapron, H. Johnsen, and R. Garello, "Wave and wind retrieval from sar images of the ocean," Ann. Telecommun., vol. 56, pp. 682-699, 2001.

[9] H. Johnsen, "Envisat ASAR wave mode product description and reconstruction procedure," ESRIN, IT-Raport IT650, 01 2005.

[10] H. Johnsen, G. Engen, and B. Chapron, "Validation of ASAR wave mode level 2 product," in IGARSS 2003 , IEEE, Ed., vol. 1, no. 1. 2003, Jul 2003, pp. 1127-1129.

[11] A. Bentamy, D. Croize-Fillon, P.Queffeulou, C. Liu, and H. Roquet, "Evaluation of high-resolution surface wind products at global and regional scales," J. Operational Ocean., vol. 2, pp. 15-27, 2009.

[12] A. Bentamy, K. B. Katsaros, M. Alberto, W. M. Drennan, and E. B. Forde, "Daily surface wind fields produced by merged satellite data," American Geophys. Union, vol. 127, pp. 343-349, 2002.

[13] M. A. Bourassa, D. M. Legler, J. J. OBrien, and S. R. Smith, "Seawinds validation with research vessels," JGR, vol. 108, pp. 343-349, 2003.

[14] N. Ebuchi, H. C. Graber, and M. J. Caruso, "Evaluation of wind vectors observed by QuikScat/seawinds using ocean buoy data," J. Atmos. Oceanic Technol., vol. 19, pp. 2049-2069, 2002.

[15] A. Bentamy, D. Croize-Fillon, and C. Perigaud, "Characterization of ASCAT measurements based on buoy and QuikScat wind vector observations," Ocean Science, vol. 4, pp. 265-274, 2008.

[16] J. A. Verspeek, A. Stoffelen, M. Portabella, H. Bonekamp, C. Anderson, and J. Figa, "Validation and calibration of ASCAT using CMOD5," IEEE Transactions on Geoscience and Remote Sensing, vol. 48, pp. 386-395, 2010.

[17] J. M. V. Ahn, J. Sienkiewcz, and P. Chang, "Operational impact of QuikScat winds at the NOAA ocean prediction center," Weather and Forecasting, vol. 21, pp. 523-539, 2006.

[18] L. Zadeh, "Fuzzy sets," Inform. Contr., vol. 8, pp. 338-353, 1965.

[19] J. C. Dunn, "A Fuzzy relative of the isodata process and its use in detecting compact, well separated cluster," Cybernetics, vol. 3, pp. 32-57, 1973.

[20] J. C. Bezdek, "Pattern recognition with Fuzzy objective function algorithms," Plenum Press, vol. 1, p. 280 , 1981.

[21] A. McBratney and J. de Gruijter, "A continuum approach to soil classification by modified Fuzzy K-MEANS with extragrades," J. of Soil Sicence, vol. 43, pp. 159-175, 1992.

[22] F. Ardhuin, B. Chapron, and F. Collard, "Observation of swell dissipation across oceans," JGR, vol. 36, pp. 1-5, 2009.

[23] B. Gjevik, O. Rygg, H. E. Krogstad, and A. Lygre, "Long period swell wave events on the Norwegian shelf,” JPO, vol. 18, pp. 724-737, 1988.

[24] E. K. Hanley, E. S. Belcher, and P. P. Sullivan, “A global climatology of windwave interaction,” JPO, vol. 40, pp. 1282-2010, 2010.

[25] M. Donelan, W. Drennan, and K. Katsaros, “The airsea momentum flux in conditions of wind sea and swell," JPO, vol. 10, pp. 32-57, 1997.

[26] S. Hasselmann, C. Bruning, K. Hasselmann, and P. Heimbach, "An improved algorithm for the retrieval of ocean wave spectra from SAR image spectra," JGR, vol. 101, pp. 16615-16629, 1996.

[27] G. Chen, B. Chapron, R. Ezaraty, and D. Vandemark, "A global view of swell and wind sea climate in the ocean by satellite altimeter and scatterometer," J. Atmos. and Oceanic Technol, vol. 19, pp. 1849-1859, 2002. 


\section{LIST OF FIGURES}

$1 \quad$ Map showing the back propagating points and respective periods using two SAR tracks for our study region. The period of the wave field (in seconds) is indicated by the color bar. The lines in black represent the ASAR tracks for Jan. 25 and 26, 2003 . . . . . . . . . . . . . . . . . . 9

2 Map showing the membership values of the swell back propagation intersection points, for the ASAR wave spectra from Jan. 25-27, 2003. The membership values are indicated by the color bar at right.

The black rectangle represents the sub-region $\left(45^{\circ}\right.$ to $80^{\circ} \mathrm{W}$ and $20^{\circ}$ to $\left.50^{\circ} \mathrm{N}\right)$ of swell convergence

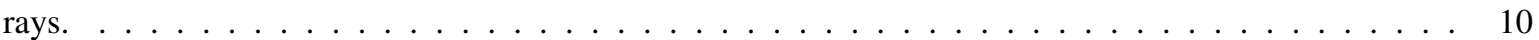

3 Maps of QuikScat wind fields and fuzzy clusters: (A) January 24, 2003; (B) February 14, 2004; (C) March 23, 2005, and (D) January 28, 2008. Maximum QuikScat wind intensity for each case was: (A) $23 \mathrm{~ms}^{-1}$; (B) $22 \mathrm{~ms}^{-1}$; (C) $26 \mathrm{~ms}^{-1}$, and (D) $25 \mathrm{~ms}^{-1}$ The membership values are indicated by the color bar at right. 


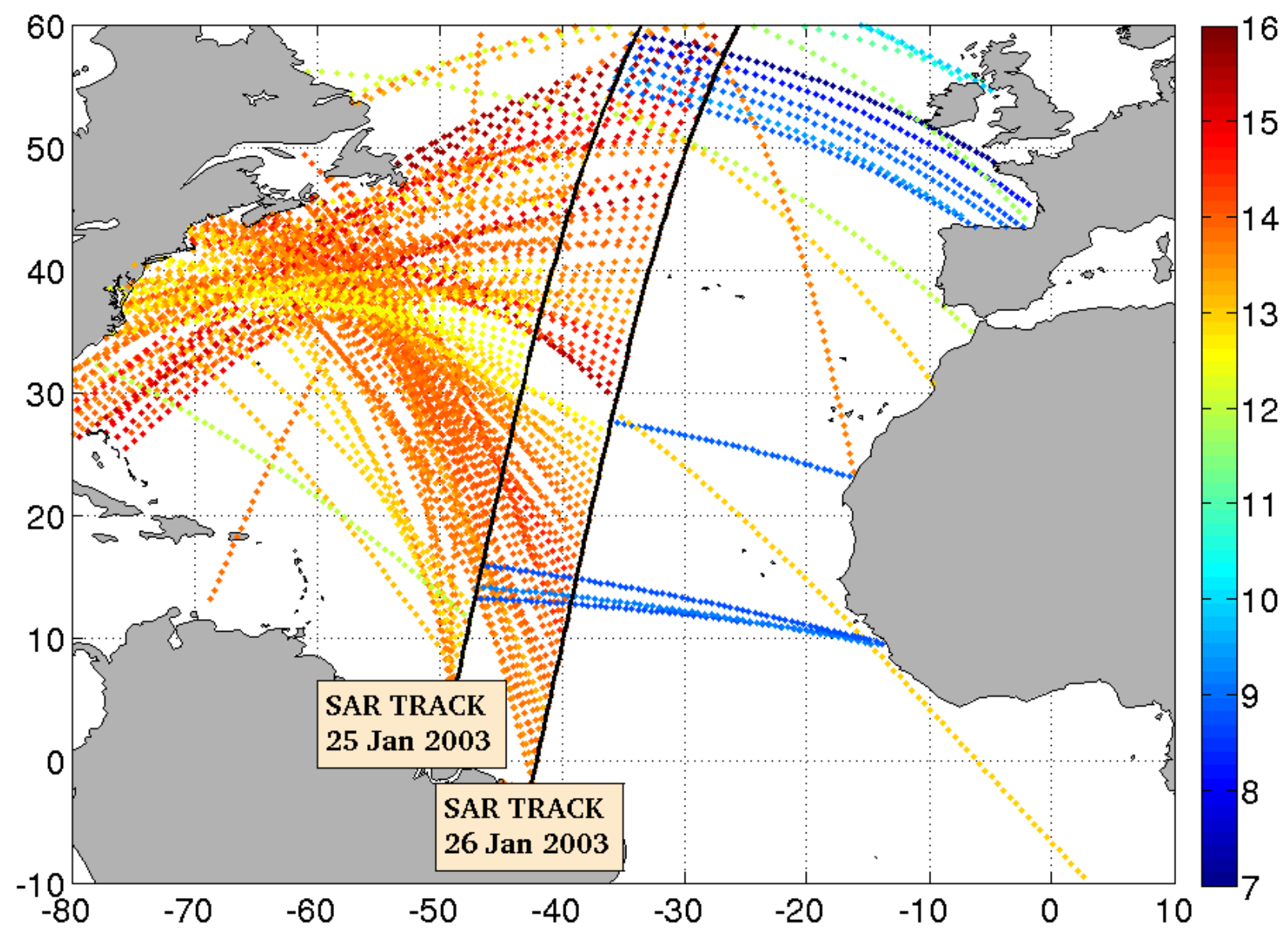

Fig. 1. Map showing the back propagating points and respective periods using two SAR tracks for our study region. The period of the wave field (in seconds) is indicated by the color bar. The lines in black represent the ASAR tracks for Jan. 25 and 26, 2003 


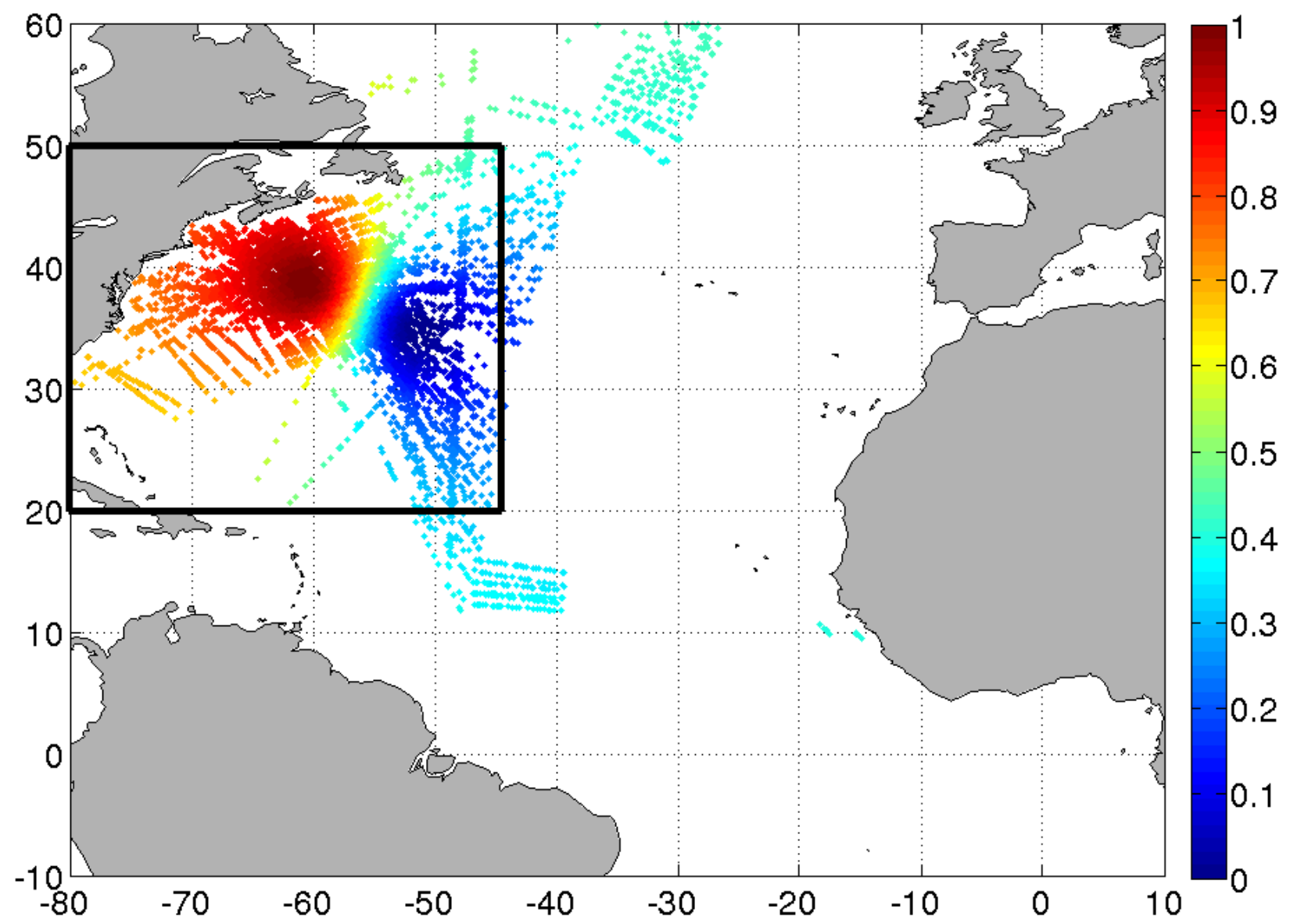

Fig. 2. Map showing the membership values of the swell back propagation intersection points, for the ASAR wave spectra from Jan. 25-27, 2003. The membership values are indicated by the color bar at right. The black rectangle represents the sub-region $\left(45^{\circ}\right.$ to $80^{\circ} \mathrm{W}$ and $20^{\circ}$ to $50^{\circ} \mathrm{N}$ ) of swell convergence rays. 

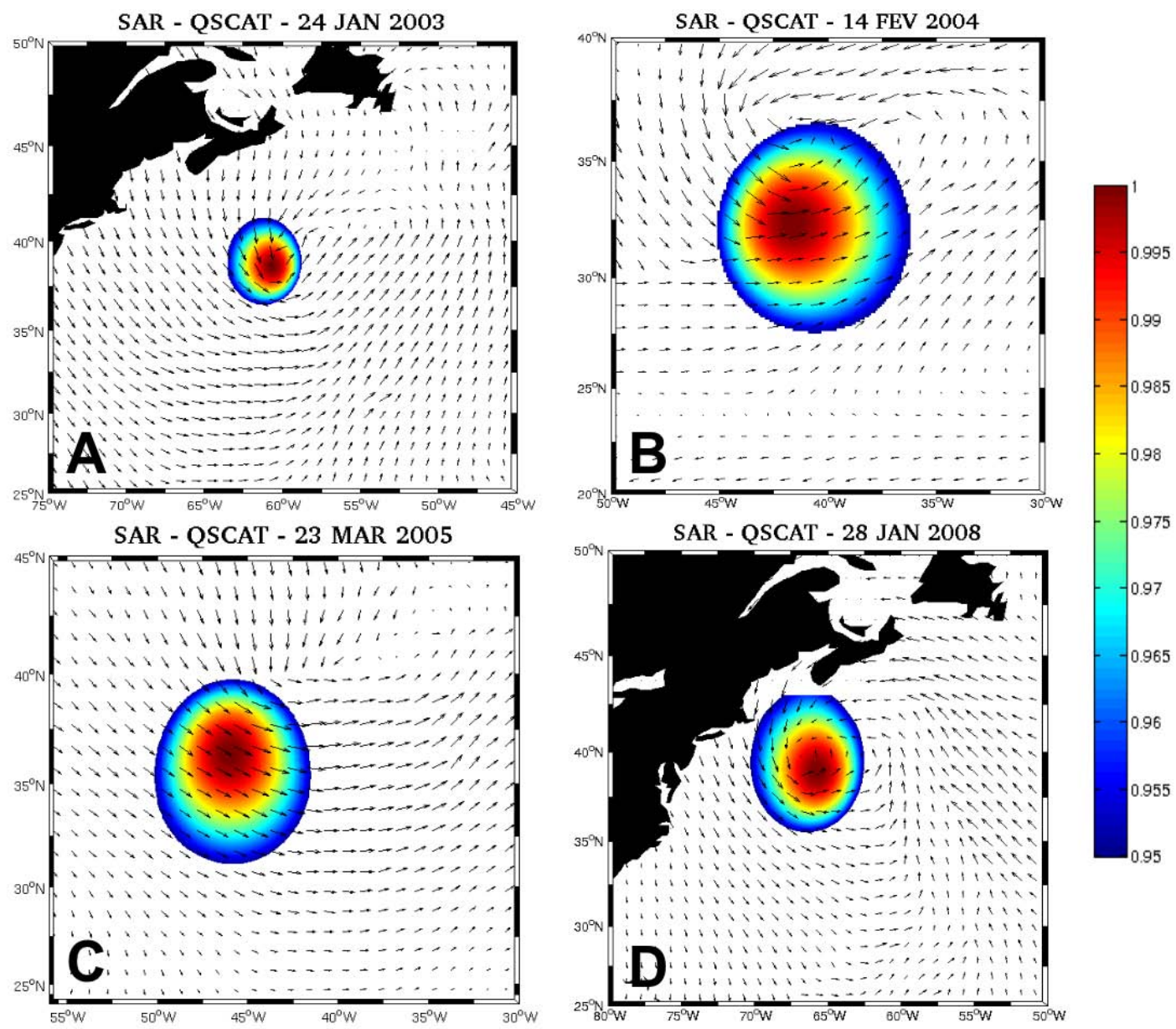

Fig. 3. Maps of QuikScat wind fields and fuzzy clusters: (A) January 24, 2003; (B) February 14, 2004; (C) March 23, 2005, and (D) January 28, 2008. Maximum QuikScat wind intensity for each case was: (A) $23 \mathrm{~ms}^{-1}$; (B) $22 \mathrm{~ms}^{-1}$; (C) $26 \mathrm{~ms}^{-1}$, and (D) $25 \mathrm{~ms}^{-1} \mathrm{The}$ membership values are indicated by the color bar at right. 
251

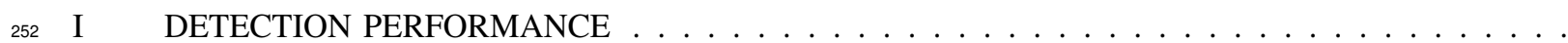


TABLE I

DETECTION PERFORMANCE

\begin{tabular}{cc}
\hline $\begin{array}{c}\text { Storm } \\
\text { ocurrence }\end{array}$ & $\begin{array}{c}\text { Distance between fuzzy center and the low } \\
\text { pressure center }\end{array}$ \\
\hline January 24, 2003 & $0^{\circ}$ \\
February 14, 2004 & $3^{\circ}$ \\
March 23, 2005 & $3.5^{\circ}$ \\
January 28, 2008 & $0.7^{\circ}$ \\
\hline
\end{tabular}

